\title{
Endoscopic Excision of Juvenile Nasopharyngeal Angiofibroma: Case Series of 20 Patients
}

\author{
Monil Parsana, ${ }^{1}$ Kalpesh Patel, ${ }^{1}$ Abhishek Gugliani ${ }^{1}$
}

\section{Introduction}

\section{ABSTRACT}

Juvenile Nasopharyngeal Angiofibroma (JNA) is a highly vascular, benign, locally aggressive tumour of the nasopharynx. Endoscopic approach is the current accepted modality for the excision of Juvenile Nasopharyngeal Angiofibroma. The current study was undertaken to assess the outcome of this procedure at our institute.

\section{Materials and Methods}

A total of 20 patients of JNA at a medical college in Ahmedabad between the period of July 2015 to July 2017 were included. The tumour was staged according to Fisch system and clinical presentation, local examination, nasal endoscopy findings, radiological findings, approach of surgical resection, complications and recurrence were noted.

\section{$\underline{\text { Results }}$}

We found that endoscopic approach for the excision of juvenile nasopharyngeal angiofibroma is safe and effective technique associated with reduced post operative morbidity and low recurrence rates.

\section{Conclusions}

JNA is a rare but a potentially life-threatening disease. All young males presenting with profuse, spontaneous and recurrent epistaxis should be evaluated for JNA. Endoscopic approaches have become the procedure of choice for resection of these tumours.

$\underline{\text { Kevwords }}$

Nasopharyngeal Neoplasms; Angiofibroma; Endoscopy

$\mathrm{J}$ uvenile Nasopharyngeal Angiofibroma (JNA) is a highly vascular, benign, locally aggressive tumour of the nasopharynx. It accounts for $0.5 \%$ of all head and neck neoplasms. It occurs typically in male adolescents in the age group of 9 to 19 years. ${ }^{1}$ Nasal obstruction and epistaxis are the most common presentation but those with advanced stages may present with facial swelling or disturbances in vision. ${ }^{2}$ Based on the extent of tumour, several staging systems have been proposed but there is no universally adopted system. ${ }^{3}$ Surgical resection of the tumour is the accepted treatment modality. ${ }^{4}$ Based on the size, location and the extent of the tumour, multiple

1 - Department of ENT, B.J Medical College and Civil Hospital, Ahmedabad, Gujarat

\section{Corresponding author:}

Dr Abhishek Gugliani

email: abhishekgugliani@gmail.com surgical approaches have been proposed. Trans-nasal endoscopic excision is an established modality and is associated with decreased morbidity. ${ }^{5}$ We present a case series of twenty patients of JNA who underwent endonasal endoscopic resection.

\section{Materials and Methods}

This is a prospective hospital-based study and was approved by the Institution Ethical Committee. A total of 20 patients of JNA presenting to the Department of E.N.T. between the period of July 2015 to July 2017 were included in the study after taking a written informed consent. All of them were operated by the same surgeon. Those patients, who were diagnosed to have malignant nasal tumours or with allergic or infective nasal pathologies, and patients who did not give consent for the study, were excluded from the study. 
Table I: Comparison of Male preponderance in JNA

\begin{tabular}{|c|c|c|c|}
\hline SEX & OUR STUDY & GHOSH ET AL. $^{6}$ & MISTRY ET AL. $^{7}$ \\
\hline Male & $100 \%$ & $100 \%$ & $100 \%$ \\
\hline Female & 0 & 0 & 0 \\
\hline
\end{tabular}

The tumour was staged according to Fisch system and basic characteristic (age), clinical presentation, local examination, nasal endoscopy findings, computer tomography and/or magnetic resonance imaging scan findings, approach of surgical resection, complications and recurrence were noted.

\section{Results}

A total of 20 cases were included in this study. The maximum and minimum age of presentation were 20 years and 12 years (Mean age $15.65 \pm 2.62$ years). All patients were male. (Table I)

The presenting complaints are shown in Fig. 1.

A diagnostic nasal endoscopy was performed in all cases. JNA appears as a red fleshy mass with irregular vessels on its surface. (Fig. 2) All patients underwent a contrast enhanced computed tomography (CECT) scan to know the extent of the disease tic resonance imaging (MRI) scan was performed in 3 cases with patients having intracranial extension. The tumour was staged according to Fisch staging. 2 cases $(10 \%)$ were staged as grade I, 7 cases (35\%) as grade II, 8 cases $(40 \%)$ as grade III and remaining 3 cases (15\%) as grade IV. We compared our findings with a similar study by $\mathrm{M}$ Jacobson et al. (Table II)

All patients underwent trans nasal endoscopic resection of tumour while 1 case with stage IV was managed by open approach of mid facial degloving along with endonasal endoscopic approach for complete removal of the tumour. External carotid artery ligation of the ipsilateral side was done in 7 patients (4 with

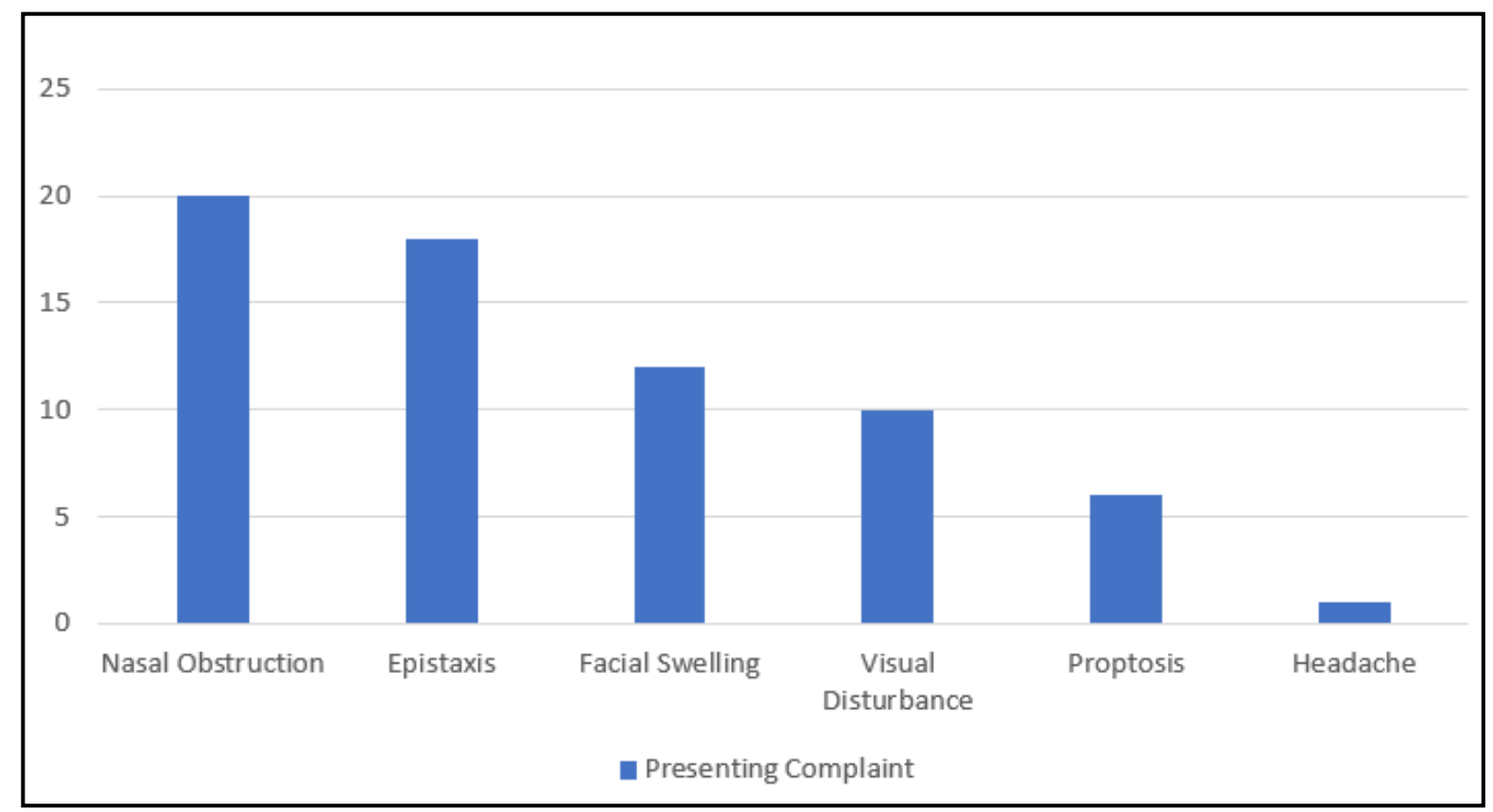

Fig. 1. Presenting complaint of patients 
Table II: Staging of the tumour at presentation

\begin{tabular}{|c|c|c|}
\hline FISCH STAGE & OUR STUDY (\%) & M JACOBSON ET AL (\%) $^{8}$ \\
\hline I & $10 \%$ & $11.10 \%$ \\
\hline II & $35 \%$ & $35.35 \%$ \\
\hline III & $40 \%$ & $40.40 \%$ \\
\hline IV & $15 \%$ & $5 \%$ \\
\hline
\end{tabular}

stage III and 3 with stage IV).

Postoperatively, they were followed up for a period of 6 months with nasal endoscopy at 1 month, 3 months and 6 months and a CECT scan at end of 6 months to look for any residual or recurrence of tumour. We did not encounter any recurrence of tumour in our study at 6 months of follow up.

\section{Discussion}

JNA affects adolescent males and is thus believed to be testosterone dependent. The peak age of presentation is about 14 years. Only 28 female cases have been reported in the literature. ${ }^{9}$ The site of origin is the posterolateral wall of the roof of nose, in the region of pterygopalatine fossa at the level of vidian canal aperture. ${ }^{10}$ It follows the path of least resistance and from the pterygopalatine fossa, it can grow medially to the nasopharynx, nasal cavity and towards the contralateral side. Laterally it can extend to the sphenopalatine and infratemporal fossa, via the pterygomaxillary fissure. Posteriorly, it can reach the internal carotid artery through the vidian canal, the cavernous sinus through the foramen rotundum and the orbital apex through the inferior orbital fissure. The blood supply of JNA is by the internal maxillary artery, the ascending pharyngeal artery or the ascending palatine artery of the ipsilateral side. ${ }^{11,12}$

Histologically, it is characterized by irregular vessels ranging from capillary and sinusoidal-type vessels to muscular vessels set in a fibrous stroma. ${ }^{13}$ Surgical resection of the tumor is considered the treatment of choice although spontaneous regression of the tumor has been reported. ${ }^{14}$ Various surgical procedures include transpalatal technique, lateral rhinotomy, midfacial degloving, infratemporal approach etc..$^{15}$

Reports of endoscopic resection of the tumor were published from Barcelona in 1993. ${ }^{16}$ Since then, with advances in the imaging techniques and better quality of endoscopes, the endonasal endoscopic technique for the resection of the tumor has gained popularity. It is associated with reduced mortality and low recurrence rates.

Nasal obstruction and epistaxis are the most common presenting complaints of patients with JNA. All young adolescent males presenting with a history of recurrent, spontaneous, profuse epistaxis should be evaluated for

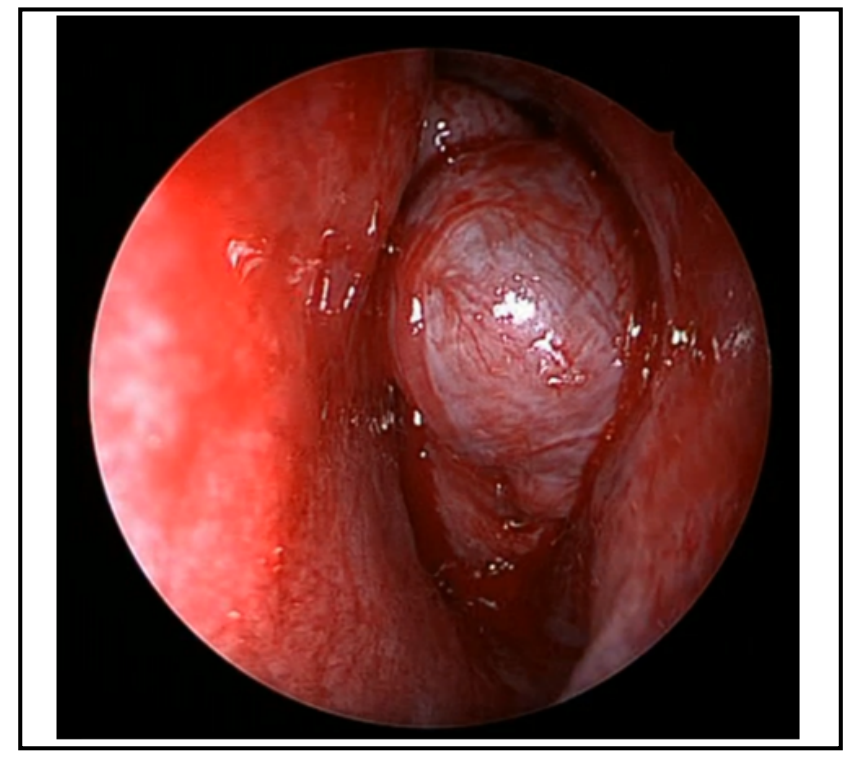

Fig. 2. Endoscopic picture of JNA in left nasal cavity 
JNA. Nasal endoscopy and CECT are usually sufficient for diagnosis. ${ }^{17}$ MRI scans may be required to assess the intracranial or intra-orbital extension of the tumor. Regular follow up is needed to assess the recurrence of the disease.

\section{Conclusion}

JNA is a rare but a potentially life-threatening disease. All young males presenting with profuse, spontaneous and recurrent epistaxis should be evaluated for JNA. A vascular nasal mass on endoscopy should raise suspicion and followed up with radiological scans. Endoscopic approaches have become the procedure of choice for resection as they have proven to be an effective alternative to the external techniques for the management of JNAs.

\section{References}

1. Chandler JR, Goulding R, Moskowitz L, Quencer RM. Nasopharyngeal angiofibromas: Staging and management. Ann Otol Rhinol Laryngol. 1984; 93:322-9

2. El Sharkawy AA, Elmorsy SM. Transnasal endoscopic management of recurrent juvenile nasopharyngeal angiofibroma. Int J Pediatr Otorhinolaryngol. 2011; 75:620-3

3. Blount A, Riley KO, Woodworth BA. Juvenile nasopharyngeal angiofibroma. Otolaryngol Clin North Am. 2011; 44:989-1004

4. Marshall AH, Bradley PJ. Management dilemmas in the treatment and follow-up of advanced juvenile nasopharyngeal angiofibroma. ORL J Otorhinolaryngol Relat Spec. 2006; 68:273-8

5. Douglas R, Wormald PJ. Endoscopic surgery for juvenile nasopharyngeal angiofibroma: where are the limits? Curr Opin
Otolaryngol Head Neck Surg. 2006; 14:1-5

6. Ghosh B, Saha S, Chandra S, Nandi TK, Bera SP. Juvenile nasopharyngeal angiofibroma-three years experience. Indian J Otolaryngol Head Neck Surg. 2003; 55(4):228-33. doi:10.1007/ BF02992425.

7. Mistry RC, Qureshi SS, Gupta S, Gupta S. Juvenile nasopharyngeal angiofibroma: A single institution study. Indian J Cancer 2005;42:35-9

8. Jacobsson M., Petruson B., Svendsen B., et al. Juvenile nasopharyngeal angiofibroma:A report of eight cases. Acta Otolaryngol. 1988; 105:132-9

9. Gruber B, Kron TK, Goldman ME, Matz G. Nasopharyngeal angiofibroma in two young children. Otolaryngol Head Surg. 1985; 93 (6): 803

10. Maroldi R, Nicolai P. Imaging in Treatment Planning for Sinonasal Diseases, Springer, New York, NY, USA, 2004

11. Lloyd G, Howard D, Lund VJ, Savy L. Imaging for juvenile angiofibroma. J Laryngol Otol. 2000; 114(9):727-30

12. Schick B, Kahle G. Radiological findings in angiofibroma. Acta Radiologica 2000; 41(6):585-93

13. Behman A, Regauer S, Behman-Schmid C, Kainz J, Stammberger H. Expression of CD34-antigen in nasopharyngeal angiofibroma. Int J Pediatr Otorhinolaryngol. 1998; 44:245-50

14. Stansbie JM, Phelps PD. Involution of residual juvenile nasopharyngeal angiofibroma. J Laryngol Otol. 1986; 100:599603

15. Hofmann T, Bernal-Sprekelsen $M$, Köele W, Reittner $P$, Klein E, Stammberger H. Endoscopic resection of juvenile angiofibromas--long term results. Rhinology 2005; 43(4): 2829

16. Anderhuber W, Stammberger H, Watch Ch, Fock CH, Regauer S, Luxenberger W, Gotschuli A. Rigid endoscopy in minimally invasive therapy of tumors of the paranasal sinuses and skull base. Min Invas Ther \& Allied Technol. 1999; 8:25-32

17. Jacobsson M, Petruson B, Svendsen P, Berthelsen B. Juvenile nasopharyngeal angiofibroma: A report of eight cases. Acta Otolaryngol. 1988; 105:132-9. 